Karen Evans

\title{
A punch, a kick, and a slap Internet resources on violence against women
}

n looking for an introduction to women and violence, the United Nations Development Fund for Women states the problem most succinctly, "Violence against women and girls is one of the most widespread violations of human rights. It can include physical, sexual, psychological and economic abuse, and it cuts across boundaries of age, race, culture, wealth and geography. It takes place in the home, on the streets, in schools, the workplace, in farm fields, refugee camps, during conflicts and crises. It has many manifestations-from the most universally prevalent forms of domestic and sexual violence, to harmful practices, abuse during pregnancy, so-called honour killings and other types of femicide." 1

It is no secret that violence knows no boundaries of race, economic standing, or education. Violence can occur within any relationship at any time. The resources below provide a wealth of information on the multitude of violence acts women can be subjected to and how they can protect themselves from the violence.

\section{United States government resources}

- Bureau of Justice Statistics: Female Victims of Violence. This electronic publication provides information on nonfatal and fatal intimate partner violence, characteristics of rape and sexual assault, and characteristics of stalking. Definitions of violence crime (homicide, rape, assault) are included. $A c$ cess: http://www.ojp.usdoj.gov/bjs/pub/ pdf/fvv.pdf.

- Centers for Disease Control (CDC): Violence Prevention. The Violence Prevention site provides information on Intimate Partner Violence (IPV) and Sexual Violence.
Information is categorized under four areas for each section. IPV offers "General Information" on a variety of topics, including Understanding Intimate Partner Violence, Preventing Violence Against Women, and the World Report on Violence and Health. "What's New" includes podcasts (When Closeness Goes Wrong), Delta Program (Domestic Violence Prevention Enhancement and Leadership Through Alliances), and Measuring Intimate Partner Victimization and Perpetration: A Compendium of Assessment Tools. "Scientific Information" offers Definitions (sexual violence, physical violence). Providing uniform definitions provides greater accuracy in research and statistical resources.

"Featured Resources" provides links to the National Domestic Hotline, Online Resource Information, and CDC's Extramural Research Program. "Sexual Violence" provides the same format at the IPV Web site. "General Information" includes Understanding Sexual Violence and Facts at a Glance. "Scientific Information" provides Definitions, Data, Risk and Protective Factors, Consequences, and Prevention Strategies. The "Featured Resources" includes links to the National Sexual Violence Resource Center and The Rape Prevention and Education Program.

The CDC Violence Prevention site provides excellent resources on violence and teen dating. "Understanding Teen Dating Abuse" is a fact sheet that provides information on the problem. CDC-TV has a video, Break the Silence: Stop the Violence available for download. Parents can use the video

Karen Evans is instruction/reference librarian at Indiana State University, e-mail: kevans4@isugw.indstate.edu (๑) 2009 Karen Evans 
to discuss relationships with their children. Choose Respect is a program for adolescents from ages 11 to 14 that helps them develop healthy relationships and avoid dating violence. Access: http://www.cdc.gov/ViolencePrevention/index.html.

- United States Department of Health and Human Services: womenshealth.gov. Womenshealth.gov is a service of the Office on Women's Health; which was established in 1991 within the Department of Health and Human Services. This site offers an assortment of information dealing with violence and women. From providing information on what constitutes abuse to providing a Safety Planning List to help those planning to leave abusers to links to state resources; this site provides a wealth of information for victims. Resources are also available by group (elder abuse, immigrants and refugee, same-sex) to assist in locating relevant information. The section on Types of Violence provides insight into what constitutes different types of violence, including dating, domestic violence, emotional and verbal, sexual assault and abuse, and stalking. Sections on Laws and Legislation, Mental Health, and Ways to Prevent and End Violence assist in making this an excellent site for information. Access: http://www.womenshealth.gov/Violence.

- United States Department of Justice: Intimate Partner Violence. Provides information on the types of intimate partner violence. Causes and Consequences, Intervention Strategies, Shelters, Murder, Suicide (risk factors, role of guns) are also covered. This site also provides links for special populations: African-American, Latino, Asian/Pacific Island, and the deaf. Access: http://www.ojp.usdoj.gov/nij/topics/crime /intimate-partner-violence/welcome.htm.

- United States Department of Justice: Office on Violence Against Women. The Office on Violence Against Women (OVW) was created in 1995 and seeks to erase several types of violence against women (domestic, dating, sexual). The site provides information on Help for Victims, including telephone numbers and links to other sites.
Additional information is provided on Domestic Violence, Sexual Assault, and Stalking; definitions; publications; and other resources are also included. OVW administers numerous grants and information is available on the variety of grants. A section entitled "The Facts About" provides information on teen dating violence, sexual violence, stalking, and domestic violence. "Fact Sheets" address topics such as the Violence Against Women Act (VAWA), Anonymous Reporting and Forensic Examinations, and Violence Against Women in Indian Country. Federal legislation, international issues, reports, and significant documents also are available. Access: http:// www.ovw.usdoj.gov/.

\section{International organizations}

- Amnesty International: Honor Kill-

ings. This site provides a fact sheet on honor killings which discusses the concept of the honor kill, the causes, and the justification for an honor killing. Access: http://www. amnestyusa.org/violence-against-women/ stop-violence-against-women-svaw/honorkillings/page.do?id=1108230.

- United Nations Development Fund for Women: UNIFEM: Violence Against Women. Established in 1976, UNIFEM works to advance women's rights and create gender equality. Statistics are reported on several areas, including Trafficking, HIV/AIDS and Violence, and Crimes Against Women in Situations of Armed Conflict. This site provides links to numerous articles of the United Nations and UNIFEM dealing with violence and women. Access: http://www.unifem.org/ gender_issues/violence_against_women/\#.

- WAVE-Women Against Violence Europe. WAVE is a network of European women's nongovernmental organizations; the organization was established in 1994 and currently works in 47 European countries, including the European Union and the Council of Europe Member Countries. The organization is currently concentrating on violence within the family and intimate relationships. Available on the WAVE site is the 2008 country report, "A Right for Protection 
and Support." The country reports covers 44 countries, providing information on population (including the percentage of women), Femicide, Domestic Violence, Services, Shelters, Marital Rape, Sexual Harassment, and Stalking. WAVE also provides information on Help Services by Country, Projects, Activities, and Publications. Information on Violence Against Women provides access to documents from the United Nations, European Union, Council of Europe, and the Organization for Security and Co-operation in Europe. Access: http://www.wave-network.org/.

- World Health Organization: Female Genital Mutilation. This site provides the key facts concerning female genital mutilation. Discusses the four major types of mutilation (Clitoridectomy, Excision, Infibulation, and Other), Causes, and Justification. Access: http://www.who.int/topics /female_genital_mutilation/en/.

\section{General resources}

- Battered Women's Justice Project. Access is provided to the Battered Women's Justice Project, the National Clearinghouse for the Defense of Battered Women, and the National Center on Full Faith and Credit. Each section provides information on their duties. The Battered Women's Justice Project presents information on murder/suicide, what police should know about arresting domestic violence suspects, economic stress and domestic violence, and how to assist battered women who stay. Access: http://www.bwjp.org.

- CRS Report for Congress: International Violence Against Women: U.S. Response and Policy Issues. This site provides information on the Types of Violence women face worldwide, the Key Issues of the subject, Social and Health Consequences, Administration Efforts, Selected United Nations and other International Efforts, Current and Emerging Issues, and U.S. legislation dealing with the topic. Access: http://www.fas.org/sgp/crs /misc/RL34438.pdf.

- emedicinehealth: Sexual Assault. A premier site on topics dealing with a sexual assault: What to do, Treatment, Forms of Sexual Assault, and Preventing an Assault. Access: http://www.emedicinehealth.com /sexual_assault/article_em.htm.

- National Center for Victims of Crime: Stalking Resource Center. The Stalking Resource Center (SRC) is a program of the National Center for Victims of Crime (NCVC). Started in 2000, it seeks to promote awareness of stalking and promote responses to the crime of stalking. This site provides a wealth of information to victims, community agencies, media, public, and law enforcement agencies. Victim assistance includes creating a safe plan, using technology in stalking cases, and creating incident and behavior log. Statistics on a variety of issues is available. SRC provides excellent coverage on laws governing stalking, including criminal, civil, federal, tribal and military. State laws and legislative updates are provided. Resources dealing with stalking are available in Spanish and are geared toward specific groups; international (Australia, United Kingdom, The Netherlands), national, and individual states. An annotated bibliography provides additional sources. Access: http:// www.ncvc.org/SRC/Main.aspx.

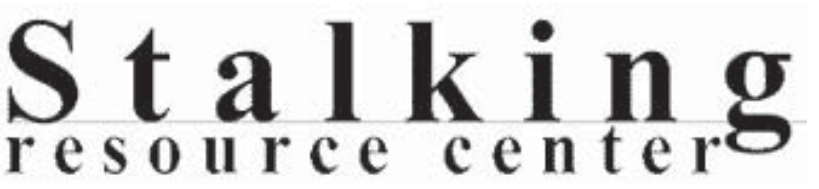

- National Coalition Against Domestic Violence. This site provides information on how victims can protect themselves, including workplace and legal guidelines. Legislative priorities, Laws (state, national, international), and Programs (Financial, Reconstructive Surgery). The Resource section provides a wealth of information, including fact sheets, state coalitions, organizations, position papers, and publications. Access: http://www. ncadv.org/.

- National Sexual Violence Resource Center (NSVRC). Founded by the Pennsylvania Coalition Against Rape, NSVRC opened in 2000. This site provides a Resource Center library, which provides access to the col- 
lections from NSVRC and the Pennsylvania Coalition Against Rape. The site also provides information on activities of the center, including Projects, Publications (types and topics are numerous), Organizations, News, and Opportunities. The Publications section alone makes this a valuable site. Access: http://www.nsvrc.org/.

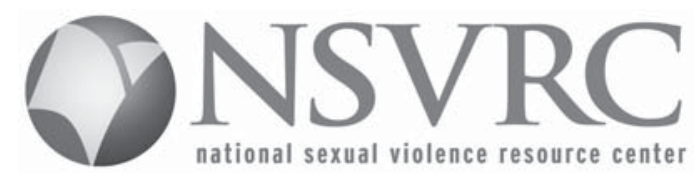

- NCVC: Violence Against Women. The National Center for Victims of Crime (NCVC) also provides information on violence against women. Domestic violence, rape-related posttramatic stress disorder, and sexual assault information is available. Access: http:// www.ncvc.org/ncvc/main.aspx?dbID =DB _ViolenceAgainstWomen155.

- Rape, Abuse and Incest National Network (RAINN). RAINN is the nation's largest organization dealing with sexual assault. This easy-to-use Web site provides ways to Get Help, Get Info, and Get Involved. The News Room provides resources including multimedia, press releases, statistics, and speakers. Access: http://www.rainn.org/.

- Toolkit to End Violence Against Women. This site provides 16 chapters on combating violence against women. Each chapter discusses a specific issue from Strengthening Community-Based Services and Advocacy for Victims to The United States Within the International CommunityResponding to Trafficking in Persons. Additional chapters highlight violence against women in the military, Native American women, and violence in sports. Access: http://toolkit.ncjrs.org/vawo_15a.html.

\section{Note}

1. United Nations Development Fund for Women: Violence Against Women. Retrieved from www.unifem.org/gender_issues/violence_against_women/. (Accessed October 25, 2009). $n$

\section{Notes}

1. Google, 2008, "Getting started with IMAP for Gmail," mail.google.com/support /bin/answer.py?hl=en\&answer=75725.

2. Mark R. Crispin, 2003, Internet Message Access Protocol-version 4rev1, ftp://ftp.rfceditor.org/in-notes/rfc3501.txt.

3. Electronic Privacy Information Center, 2004, Gmail Privacy Page, epic.org/privacy /gmail/faq.html.

4. Tim O'Reilly, 2004, "The fuss about Gmail and privacy: nine reasons why it's bogus," www.oreillynet.com/pub $/$ wlg/4707.

5. How-to Geek, 2007, "Use Gmail IMAP in Microsoft Outlook 2007," www.howtogeek.com/howto/microsoft-office/use-gmail -imap-in-microsoft-outlook-2007.

6. How-to-Geek, 2008, "Prevent Outlook with Gmail IMAP from showing duplicate tasks in the To-do Bar," www.howtogeek.com/howto/microsoft-office/prevent -outlook-with-gmail-imap-from-showing -duplicate-tasks-in-the-to-do-bar/. $n$ 